\title{
Methodological framework for development of competence standards for optical diagnosis in gastrointestinal endoscopy: European Society of Gastrointestinal Endoscopy (ESGE) Position Statement
}

Authors

Britt B. S. L. Houwen ${ }^{1} \odot$, Cesare Hassan ${ }^{2,3}$, Yark Hazewinkel ${ }^{4}$, Jasper L. A. Vleugels ${ }^{1}$, Mario Dinis-Ribeiro ${ }^{5,6}$, Marjolein J. E. Greuter ${ }^{7}$, Veerle M. H. Coupé7, Evelien Dekker ${ }^{1} \odot$ Raf Bisschops $^{8} \odot$

Institutions

1 Department of Gastroenterology and Hepatology, Amsterdam University Medical Center, location AMC, University of Amsterdam, Amsterdam, The Netherlands

2 Department of Biomedical Sciences, Humanitas University, Pieve Emanuele, Milan, Italy

3 Endoscopy Unit, IRCCS Humanitas Clinical and Research Center, Rozzano, Milan, Italy

4 Department of Gastroenterology and Hepatology, Radboud University Medical Center, Radboud University, Nijmegen, The Netherlands

5 Porto Comprehensive Cancer Center (Porto.CCC), Porto, Portugal

6 RISE@CI-IPOP (Health Research Network), Porto, Portugal

7 Department of Epidemiology and Data Science, Amsterdam University Medical Center, location VUmc, Amsterdam, The Netherlands

8 Department of Gastroenterology and Hepatology, Catholic University of Leuven (KUL), TARGID, University Hospital Leuven, Leuven, Belgium published online 3.12 .2021

Bibliography

Endoscopy 2022; 54: 84-87

DOI 10.1055/a-1689-5615

ISSN 0013-726X

(C) 2021. European Society of Gastrointestinal Endoscopy

All rights reserved.

This article is published by Thieme.

Georg Thieme Verlag KG, Rüdigerstraße 14,

70469 Stuttgart, Germany

Corresponding author

Raf Bisschops, MD PhD, Department of Gastroenterology and Hepatology, University Hospital Leuven, KU Leuven, Herestraat 49, 3000 Leuven, Belgium

raf.bisschops@uzleuven.be

\section{SOURCE AND SCOPE}

This Position Statement is an official statement of the European Society of Gastrointestinal Endoscopy (ESGE). ESGE has a vision to create a thriving community of endoscopy services and endoscopists in Europe, to provide a high quality of endoscopy care. This position statement provides a methodological framework for the development of easy-to-measure competence standards that are focused on clinical consequences of optical diagnosis. The methodological framework presented has been established by a task force of experts in optical diagnosis who were involved in the ESGE Curricula Working Group for optical diagnosis training.
The importance of defining standards for optical diagnosis

Optical diagnosis has an increasingly important role in current endoscopy practice because of the development of advanced imaging techniques and breakthroughs in artificial intelligence $(\mathrm{Al})$. Accurate optical diagnosis is an important skill to guide clinical decisions in endoscopy [1]. Accurate optical diagnosis helps in choosing the appropriate resection method and surveillance interval, thereby avoiding under- and overtreatment, and saving costs. ESGE has developed a core curriculum for optical diagnosis practice across Europe for high quality optical diagnosis training [1,2]. The development of easy-to-measure competence standards that are focused on 
the clinical consequences of optical diagnosis could help to optimize clinical management in gastrointestinal endoscopy.

\section{Initial process}

In 2020, the ESGE board established an expert-derived task force in order to develop a methodological framework for developing competence standards for optical diagnosis in gastrointestinal endoscopy. This task force is a spin-off of the Curricula Working Group for optical diagnosis training [1,2]. The aim of this Position Statement is to propose a methodological framework that can be used to define easy-to-measure competence standards for optical diagnosis that are focused on clinical consequences.

\section{Task force on optical diagnosis competence standards}

The ESGE task force on optical diagnosis competence standards comprises members who were appointed by the chair after ESGE Governing Board approval. They include members of the ESGE and, in selected cases, representatives of other medical or nonmedical societies. The list of current members will be published on the ESGE website. The main duty of the task force is to propose topics for new optical diagnosis standards and to participate in their detailed preparation.

\section{Selection of topics}

The members of the task force on optical diagnosis competence standards will propose optical diagnosis competence standards topics to the ESGE Governing Board, which will select and prioritize them. Criteria for selection will include the clinical relevance of the optical diagnosis competence standard. As a first step, in 2021, the ESGE task force on optical diagnosis competence standards for diminutive colorectal polyps was initiated (the resulting Position Statement is published in this issue [3]). We anticipate activating additional initiatives for other diseases managed by upper and lower gastrointestinal endoscopy.

\section{Selection of working group members}

For the development of each optical diagnosis competence standard, a specific task force will be formed. A task force generally will involve around 10 members, including a leader. All groups will be composed of candidates who are selected by the task force leader. Each task force will write a position statement manuscript that will be distributed for review to ESGE members.

\section{Methodological framework for the development of competence standards for optical diagnosis in gastrointestinal endoscopy}

$(\triangleright$ Table 1$)$

\section{Step 1: Definition of the main categories and clinical consequences of optical diagnosis}

For each topic, the main categories of optical diagnosis outcomes will be identified according to their clinical usefulness and current ability to predict the histology. In addition, the potential positive and negative clinical consequences of performing optical diagnosis will be mapped ( $>$ Table 2 ).

\section{Step 2: Systematic review of the literature and/or simulation approach}

In order to assess the potential clinical benefits or harms of implementing optical diagnosis with different standards, a systematic literature search will be performed or updated if available. When possible, and if needed, a simulation approach could be performed to quantify the expected benefit and harm related to different optical diagnostic competence standards. For diminutive colorectal polyps, a simulation approach has already been extensively described [4].

\section{Step 3: Delphi consensus procedure}

To establish safe and easy-to-measure standards for optical diagnosis, clinically acceptable consequences of implementing this standard need to be chosen. Therefore, a panel of European experts in optical diagnosis will be asked to participate in a minimum three-round Delphi process to reach consensus on competence standards [5-7], based on the literature search and, if available, a simulation model. All participating experts will be asked to vote online on the potential options for competence standards for optical diagnosis.

For each competence standard option, the evidence in the literature about the potential clinical benefits or harms of implementing optical diagnosis will be shown. If available, the clinical consequences, as estimated by a simulation study, will also be shown. For a standard to be accepted, at least 10 experts have to vote on these options. The standards with consensus will form the new competence standards for

- Table 1 Step-wise description of the roadmap for the development of competence standards for optical diagnosis in gastrointestinal endoscopy.

Step 1 Definition of the main categories and clinical consequences of optical diagnosis

Step 2 Systematic review of the literature and/or simulation approach to assess the clinical consequences for different competence standards of optical diagnosis

Step 3 Delphi consensus procedure to reach consensus on competence standards for optical diagnosis 
- Table 2 Example main categories (input) and clinical consequences (output) for optical diagnosis curriculum topics.

\begin{tabular}{|c|c|c|c|}
\hline Topic & Main categories (input) & $\begin{array}{l}\text { Potential positive consequences of } \\
\text { correct optical diagnosis (output) }\end{array}$ & $\begin{array}{l}\text { Potential negative consequences of } \\
\text { incorrect optical diagnosis (output) }\end{array}$ \\
\hline $\begin{array}{l}\text { Esophageal squamous cell } \\
\text { cancer (ESCC) }\end{array}$ & $\begin{array}{l}\text { Non-neoplastic; intramu- } \\
\text { cosal ESCC; ESCC invading } \\
\text { muscularis mucosae/SM1; } \\
\geq \text { SM2 ESCC }\end{array}$ & $\begin{array}{l}\text { Appropriate treatment } \\
\text { (i.e. no resection, endoscopic } \\
\text { resection, surgery) }\end{array}$ & $\begin{array}{l}\text { Inappropriate treatment (i. e. un- } \\
\text { necessary surgery or an unnecessary } \\
\text { endoscopic attempt) }\end{array}$ \\
\hline Barrett's esophagus & Non-neoplastic; neoplastic & $\begin{array}{l}\text { Appropriate treatment } \\
\text { (i. e. no resection, endoscopic } \\
\text { resection, surgery) }\end{array}$ & $\begin{array}{l}\text { Inappropriate treatment (i. e. un- } \\
\text { necessary surgery or an unnecessary } \\
\text { endoscopic attempt) }\end{array}$ \\
\hline \multirow[t]{2}{*}{ Stomach } & $\begin{array}{l}\text { Non-neoplastic versus neo- } \\
\text { plastic lesion }\end{array}$ & $\begin{array}{l}\text { Appropriate treatment } \\
\text { (i.e. no resection, endoscopic } \\
\text { resection, surgery) }\end{array}$ & $\begin{array}{l}\text { Inappropriate treatment (i. e. un- } \\
\text { necessary surgery or an unnecessary } \\
\text { endoscopic attempt) }\end{array}$ \\
\hline & $\begin{array}{l}\text { Intestinal metaplasia } \\
\text { versus no intestinal meta- } \\
\text { plasia (EGGIM score) }\end{array}$ & $\begin{array}{l}\text { Appropriate selection of patients for } \\
\text { surveillance }\end{array}$ & $\begin{array}{l}\text { Inappropriate selection of patients } \\
\text { for surveillance (overtreatment) or } \\
\text { inappropriate discharge of patients } \\
\text { that need surveillance }\end{array}$ \\
\hline Diminutive colorectal polyps & $\begin{array}{l}\text { Adenoma; sessile serrated } \\
\text { lesion; hyperplastic polyp }\end{array}$ & $\begin{array}{l}\text { Neoplastic and non-neoplastic le- } \\
\text { sions that would be resected and } \\
\text { discarded (i. e. reduction in histo- } \\
\text { pathological analysis); non-neoplastic } \\
\text { lesions that would remain in situ in } \\
\text { the rectosigmoid (i. e. reduction in } \\
\text { unnecessary polypectomies, reduc- } \\
\text { tion in histopathological analysis) }\end{array}$ & $\begin{array}{l}\text { Too long/too short surveillance } \\
\text { intervals; neoplastic lesions that } \\
\text { remain in situ in the rectosigmoid }\end{array}$ \\
\hline Early colorectal cancer (eCRC) & $\begin{array}{l}\text { Low grade neoplasia; high } \\
\text { grade neoplasia/eCRC (SM1 } \\
\text { or }<1 \mathrm{~mm} \text { ); eCRC (SM2, } 3 \text {, } \\
\text { or }>1 \mathrm{~mm} \text { ) }\end{array}$ & $\begin{array}{l}\text { Appropriate treatment } \\
\text { (i. e. piecemeal endoscopic mucosal } \\
\text { resection, en bloc resection, } \\
\text { surgery) }\end{array}$ & $\begin{array}{l}\text { Inappropriate treatment (i. e. un- } \\
\text { necessary surgery or an unnecessary } \\
\text { or incorrect endoscopic attempt) }\end{array}$ \\
\hline $\begin{array}{l}\text { Dysplasia in inflammatory } \\
\text { bowel disease }\end{array}$ & Non-neoplastic; neoplastic & $\begin{array}{l}\text { Appropriate treatment } \\
\text { (i.e. no resection, endoscopic } \\
\text { resection, surgery) }\end{array}$ & $\begin{array}{l}\text { Inappropriate treatment (i. e. un- } \\
\text { necessary surgery or an unnecessary } \\
\text { or incorrect endoscopic attempt) }\end{array}$ \\
\hline
\end{tabular}

optical diagnosis. A standard will be accepted if at least $80 \%$ agreement is reached after a minimum of two voting rounds. Participating experts will be asked to rate their agreement using a five-point Likert scale: "Strongly Agree," "Agree," "Neither Agree nor Disagree," Disagree," "Strongly Disagree." Experts agree on the standard if they vote "Strongly Agree" or "Agree."

Standards will be adapted and/or excluded during iterative rounds of discussion of the comments and suggestions made by the experts during the modified Delphi process. If there is extensive discussion and if there are changes to or adaptation of a statement, a new Delphi round will be initiated to test the consensus on the specific statement. The evolution and adaptation of the minimum standards during the Delphi process will be documented. Experts will be asked to leave a comment if they are undecided or disagree on a specific standard. At the end, an open text box is provided for participants to include comments relating to items, if desired. The final results will be circulated to all experts for review and comment.

\section{Conclusion and future prospects}

This ESGE Position Statement provides a clear and comprehensive methodological framework that can be used for the development of standards for optical diagnosis in gastrointestinal endoscopy. The optical diagnosis standards that will be produced in the coming years will be a first step in optimizing treatment and surveillance interval decisions. After finalization of the development of competence standards, prospective evaluation of these standards will be necessary. Eventually, incorporating these standards into ESGE certification for optical diagnosis training could be the ultimate objective.

\section{Disclaimer}

ESGE Guidelines and Position Statements represent a consensus of best practice based on the available evidence at the time of preparation. They might not apply in all situations and should be interpreted in the light of specific clinical situations and resource availability. Further controlled clinical studies may be needed to clarify aspects of these statements, and revi- 
sion may be necessary as new data appear. Clinical considerations may justify a course of action at variance with these recommendations. ESGE Guidelines and Position Statements are intended to be an educational device providing information that may assist endoscopists in providing care to patients. They are not rules and should not be construed as establishing a legal standard of care or as encouraging, advocating, requiring, or discouraging any particular treatment.

\section{Acknowledgments}

R. Bisschops is supported by the Research Foundation Flanders (FWO).

\section{Competing interests}

R. Bisschops has received consultancy and speaker's fees from Fujifilm and Pentax (both 2015 to present); his department has received research grants from Fujifilm and Pentax (both 2015 to present). E. Dekker has received speaker's fees from Roche (2018), Norgine (2019), Olympus and GI Supply (both 2019 to 2020), and Fujifilm (2020), and has provided consultancy to Fujifilm (2018), CPP-FAP (2019), GI Supply (2019 to 2020), Olympus (2020 to present), PAION and Ambu (both 2021); she received a research grant from Fujifilm (2017 to 2020) and her department has equipment on loan from Fujifilm (2017 to present) and Olympus (2021). C. Hassan has received research support from Fujifilm (2017 to present); his department has received support from Sonoscape. M. Dinis-Ribeiro is co-editor inchief of Endoscopy. V.M.H. Coupé, M.J.E. Greuter, Y. Hazewinkel, B.B. S.L. Houwen, and J.L.A. Vleugels declare that they have no conflict of interest.

\section{References}

[1] Dekker E, Houwen B, Puig I et al. Curriculum for optical diagnosis training in Europe: European Society of Gastrointestinal Endoscopy (ESGE) Position Statement. Endoscopy 2020; 52: 899-923

[2] Bisschops R, Dekker E, East JE et al. European Society of Gastrointestinal Endoscopy (ESGE) curricula development for postgraduate training in advanced endoscopic procedures: rationale and methodology. Endoscopy 2019; 51: 976-979

[3] Houwen BBSL, Hassan C, Coupé VMH et al. Definition of competence standards for optical diagnosis of diminutive colorectal polyps: European Society of Gastrointestinal Endoscopy (ESGE) Position Statement. Endoscopy 2021; 53: doi:10.1055/a-1689-5130

[4] Houwen BBSL, Greuter MJE, Vleugels JLA et al. Guidance for setting easy-to-adopt competence criteria for optical diagnosis of diminutive colorectal polyps: a simulation approach. Gastrointest Endoscopy 2021; 94: 812-822.e43

[5] Jones ], Hunter D. Consensus methods for medical and health services research. BMJ 1995; 311: 376

[6] Boulkedid R, Abdoul H, Loustau M et al. Using and reporting the Delphi method for selecting healthcare quality indicators: a systematic review. PloS One 2011; 6: e20476

[7] Humphrey-Murto S, de Wit M. The Delphi method - more research please. J Clin Epidemiol 2019; 106: 136-139 